\title{
Factors causing insomnia in postmenopausal women
}

\author{
IWONA EWA KARPETA-PAWLAK ${ }^{A-F}$, WERONIKA WOLIŃSKA ${ }^{\mathrm{B}, \mathrm{D}, \mathrm{E}}$, BOŻENA MROCZEK ${ }^{\mathrm{A}, \mathrm{D}, \mathrm{E}, \mathrm{G}}$
}

Department of Human Sciences in Medicine, Pomeranian Medical University, Szczecin, Poland

A - Study Design, B - Data Collection, C - Statistical Analysis, D - Data Interpretation, E - Manuscript Preparation, F - Literature Search, G - Funds Collection

Summary Background. Insomnia is the most common sleep disorder among adult people. It causes tiredness, difficulties in focusing, loss of energy, increased sensitivity, and irritability. Insomnia may develop into a chronic sleep disorder which has a direct negative impact on the quality of life of the affected person and it limits their capabilities of functioning in society.

Objectives. The study objective was to seek relationships between age, the use of HRT, occurrence of depression symptoms and chronic conditions and insomnia in postmenopausal women.

Material and methods. The study was conducted on 128 women, students of the University of the Third Age in Stargard. The median age was 65 years and ranged from 47 to 82 years old. The study was conducted with the use of the Insomnia Severity Index, the Beck Depression Inventory and the authors' own questionnaire.

Results. Various degrees of insomnia were diagnosed in 69 women (53.91\%). A statistically significant relationship was found between insomnia and age $\left(x^{2}=27.48 ; p=0.007\right)$, occurrence of depression $\left(x^{2}=12.93 ; p=0.005\right)$, and depression symptoms $\left(x^{2}=81.86\right.$; $p<0.001)$. The study revealed no statistically significant relationship between insomnia and the use of HRT, or the existence of chronic conditions.

Conclusions. Age and depression symptoms have a significant impact on the occurrence of insomnia. However, the use of HRT or preexisting chronic conditions have no key influence on the occurrence of insomnia.

Key words: insomnia, Insomnia Severity Index (ISI), Beck Depression Inventory (BDI), chronic conditions, HRT.

Karpeta-Pawlak IE, Wolińska W, Mroczek B. Factors causing insomnia in postmenopausal women. Fam Med Prim Care Rev 2017; 19(3): 225-229, doi: https://doi.org/10.5114/fmpcr.2017.69280.

\section{Background}

In previous studies the authors dealt with insomnia in 60-year-olds, where a statistically significant association of insomnia with hypertension, asthma/COPD, atherosclerosis and depression was found. In this study the severity of insomnia was directly related to the age of the respondents. It has been shown that severe and moderate insomnia were more common among people aged 70 years and more. In the following work the researchers narrowed the study group to postmenopausal women. This was due to the well-known effects of menopause and the time after this period, and its effects on women's lives, including their sleep [1]. In the contemporary world, sleep disorders have become very common due to modern technologies, unhealthy lifestyles and social development [2]. Sleep disorders include: conditions related to increased sleepiness, insomnia and disturbances in the sleep-wake cycle [3]. One of the most common health problems in adults, constituting $90 \%$ of all sleep disorders, is insomnia. Due to the common nature of this condition, it may be considered a civilization disease of the 21st century [2]. In ICD-10 insomnia is defined as an insufficient amount and/or quality of sleep occurring at least 3 times a week for at least a month $[4,5]$. The causes of insomnia include: stress, personal problems, improper lifestyle, and using psychoactive substances. These causes may be related to professional or family life, as well as various personal failures and problems. People all around the world suffer from insomnia, but there are differences at the international level revealing the influence of geographical and socio-cultural factors on insomnia. These factors include, among others, climate, the pace of life of people, political conflicts, economic crisis, and the popularity of psychoactive substances. Insomnia causes tiredness, difficulties in focusing, loss of energy, increased sensitivity, and irritability. Incidental sleep disorders should not be a cause for alarm, but if their frequency increases and they become prolonged, they may impact an individual's quality of life and limit their ability to function in society [6]. Insomnia may be a result, symptom or cause of underlying condition, for example, an insufficient amount or quality of sleep are prodromal symptoms of depression [7]. In women undergoing menopause insomnia is one of many symptoms of that stage in their life [8]. Insomnia may also be the outcome of respiratory system conditions [9].

Sleep disorders become more pronounced in people older than 65 . This is related to a decrease in the number of neurons, and shortening of the deep sleep stage, while the light sleep stage becomes longer. While the amount of sleep remains the same, the rapid eye movement stage becomes extended. This leads to a shortening of sleep and frequent waking up in the second part of the night [10]. Insomnia in older people is mostly caused by various conditions rather than the process of ageing. For this reason, it is considered that insomnia is caused by medical conditions which include chronic pain, somatic conditions of the respiratory, neurological and cardio-vascular systems, mental health disorders (depression) and taken medication $[10,11]$.

Insomnia among older people is twice more frequently diagnosed in women than men. Sleeping disorders in women may be related to menopause [8]. Problems with falling asleep, bad quality of sleep or irregular sleep are caused by an increase in the concentration of follicle-stimulating hormone (FSH), luteinising hormone (LH), and a decrease in oestrogen and progesterone secretion $[8,10,11]$. Sleep disorders may have their origins in hormonal changes due to menopause. Vasomotor symptoms and sleep disorders are often associated with perimenopausal and postmenopausal women. These are the key menopause 
symptoms occurring in this stage of women's life. Insomnia is one of many symptoms of menopause which may be regulated with hormone replacement therapy (HRT) [8].

Based on the collected data the researchers would like to broaden their knowledge regarding the occurrence of insomnia-predisposing risk factors in postmenopausal women. The hypothesis stands that age, chronic conditions and depression symptoms have a strong influence on the occurrence of sleep disorders in postmenopausal women. The second hypothesis states that the use of HRT is an efficient sleep disorder preventive measure for women.

\section{Objectives}

The study objective was to seek relationships between age, the use of HRT (hormone replacement therapy), occurrence of depression symptoms and chronic conditions and insomnia in postmenopausal women.

\section{Material and methods}

128 women participated in the study - students of the University of the Third Age in Stargdard, Zachodniopomorskie region. The study was conducted in March 2015. The median age was 65 years and ranged from 47 to 82 years. The Shapiro-Wilk test was performed to show that there was no normal distribution for the respondents' age in the study. The Insomnia Severity Index (ISI), the Beck Depression Inventory (BDI), and the authors' own questionnaire were used.

The Insomnia Severity Scale is often used in studies related to menopause. With the use of this tool an increase of insomnia in postmenopausal women is noticeable up to $60 \%$, and up to $40 \%$ in postmenopausal women. This scale is also a reliable tool in measuring the influence of HRT on sleep disorders. It consists of 7 questions. Each of them is based on a 5-point Likert scale (from 0 to 4). The respondent scores from 0 to 28 points. The results of the Insomnia Severity Scale are interpreted in the following way: 0-7 indicates lack of insomnia, 8-14 points is mild insomnia, 15-21 points is moderate insomnia, and 22-28 indicates severe insomnia [12-14]. The Beck Depression Inventory $(\mathrm{BDI})$ is a scale used in diagnosing depression. It consists of 21 questions, where each one has 4 possible answers. The scale is interpreted in the following way: severe depression (28 points and more), moderate depression (11-27 points), and lack of depression/bad mood (0-10 points) $[15,16]$. The authors' own questionnaire contains questions regarding the age of respondents, existing chronic conditions, and the use of HRT. In this questionnaire the question of the occurrence of chronic diseases included: osteoporosis, asthma or COPD, hypertension, diabetes, depression, neoplasms and unclassified arthritis of a broader nature. The incidence of malignancy was included in the neoplasms (benign and malignant neoplasms were included) and their duration (current and past). As for the concept of unclassified arthritis, it refers to situations of seropositive and seronegative arthritis, osteoarthrosis process and joint pain.

The study received the positive opinion of the Bioethical Commission (no. KB-0012/63/16).

\section{Statistical methods}

The obtained results were statistically analysed with the use of PQStat software and Excel sheet. The article contains descriptive statistics and a statistical test. The first stage involved creating a database, followed by the Pearson $\mathrm{chi}^{2}$ test for independence. A statistical significance of $p<0.05$ was established in the study.

\begin{tabular}{|l|l|}
\hline \multicolumn{2}{|l|}{ Table 1. Characteristics of the respondents } \\
\hline Variable & $n(\%)$ \\
\hline Age [years] & $\begin{array}{l}\text { median }=65 \text { years } \\
\text { min }=47 \text { years } \\
\text { max }=82 \text { years }\end{array}$ \\
\hline $\begin{array}{l}\text { Chronic diseases: } \\
\text { - neoplasms }\end{array}$ & $8(6.25 \%)$ \\
- onclassified arthritis & $30(23.44 \%)$ \\
- asthma/COPD & $37(28.91 \%)$ \\
- diapertension & $27(21.09 \%)$ \\
\hline Hormone replacement therapy: & $62(48.44 \%)$ \\
- yes & $24(18.75 \%)$ \\
- no & $12(9.38 \%)$ \\
\hline
\end{tabular}

\section{Results}

Insomnia of various severity was diagnosed in 69 women (53.91\%). In 4 respondents (3.12\%) severe insomnia was diagnosed, in 20 people $(15.63 \%)$ moderate insomnia, mild insomnia in 45 women (35.16\%), and 59 women did not suffer from insomnia.

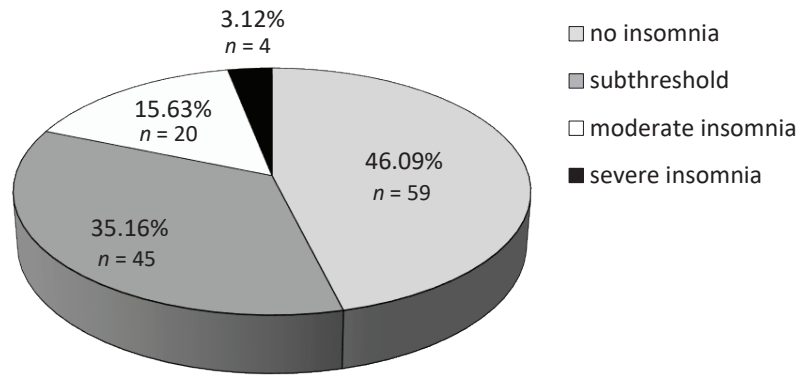

Figure 1. Results of Insomnia Severity Scale

Figure 2 presents the influence of age on insomnia occurrence in postmenopausal women. The results indicate that insomnia increases in women aged 61-70. Analysis showed that there is a statistically significant relationship between age and insomnia, where $x^{2}=27.48$, and $p=0.007$. Severe insomnia occurs in respondents in the age range 51-60 (1 person - 25\%) and $61-70$ ( 3 people $-75 \%$ ). Moderate insomnia occurs in all age ranges: $0-50$ ( 5 people $-25 \%)$, 51-60 ( 2 people $-10 \%$ ),

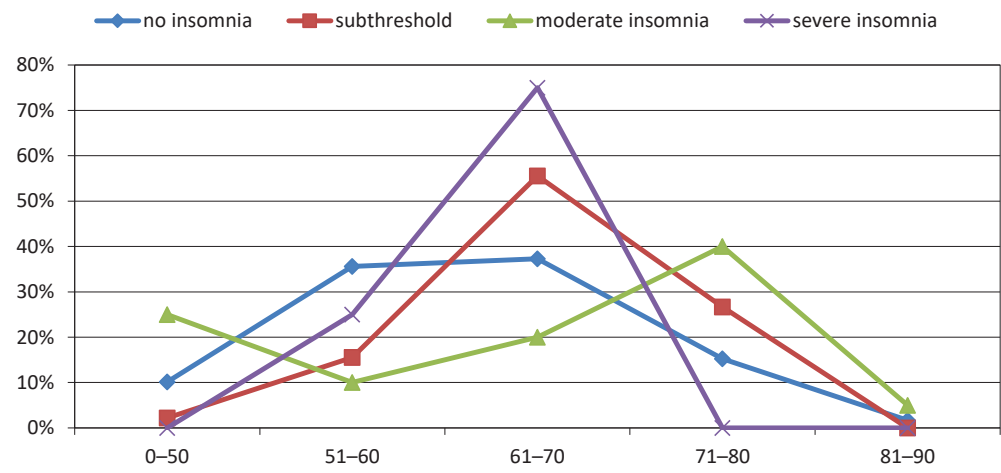

Figure 2. Influence of age of respondents on insomnia occurrence 


\begin{tabular}{|c|c|c|c|c|c|c|c|}
\hline \multirow{2}{*}{\multicolumn{2}{|c|}{ Variable }} & \multicolumn{4}{|c|}{ Insomnia Severity Scale } & \multirow[t]{2}{*}{$x^{2}$} & \multirow[t]{2}{*}{$p$} \\
\hline & & \multirow[t]{2}{*}{ no insomnia } & \multirow[t]{2}{*}{ subthreshold } & \multirow[t]{2}{*}{ moderate insomnia } & \multirow[t]{2}{*}{ severe insomnia } & & \\
\hline \multicolumn{2}{|c|}{ Chronic diseases } & & & & & & \\
\hline \multirow[t]{2}{*}{ Depression } & yes & $2(3.39 \%)$ & $4(8.89 \%)$ & $4(20 \%)$ & $2(50 \%)$ & \multirow[t]{2}{*}{12.93} & \multirow[t]{2}{*}{0.005} \\
\hline & no & $57(96.61 \%)$ & $41(91.11 \%)$ & $16(80 \%)$ & $2(50 \%)$ & & \\
\hline \multirow[t]{2}{*}{ Diabetes } & yes & $11(18.64 \%)$ & $9(20 \%)$ & $3(15 \%)$ & $1(25 \%)$ & \multirow[t]{2}{*}{0.33} & \multirow[t]{2}{*}{0.95} \\
\hline & no & $48(81.36 \%)$ & $36(80 \%)$ & $17(85 \%)$ & $3(75 \%)$ & & \\
\hline \multirow[t]{2}{*}{ Hypertension } & yes & $23(38.98 \%)$ & $25(55.56 \%)$ & $13(65 \%)$ & $1(25 \%)$ & \multirow[t]{2}{*}{6.10} & \multirow[t]{2}{*}{0.11} \\
\hline & no & 36 (61.02\%) & $20(44.44 \%)$ & $7(35 \%)$ & $3(75 \%)$ & & \\
\hline \multirow[t]{2}{*}{ Asthma/COPD } & yes & $10(16.95 \%)$ & $12(26.67 \%)$ & $5(25 \%)$ & $0(0 \%)$ & \multirow[t]{2}{*}{2.70} & \multirow[t]{2}{*}{0.44} \\
\hline & no & 49 (83.05\%) & $33(73.33 \%)$ & $15(75 \%)$ & $4(100 \%)$ & & \\
\hline \multirow[t]{2}{*}{ Osteoporosis } & yes & $15(25.42 \%)$ & $14(31.11 \%)$ & $7(35 \%)$ & $1(25 \%)$ & \multirow[t]{2}{*}{0.85} & \multirow[t]{2}{*}{0.84} \\
\hline & no & $44(74.58 \%)$ & $31(68.89 \%)$ & $13(65 \%)$ & $3(75 \%)$ & & \\
\hline \multirow{2}{*}{$\begin{array}{l}\text { Unclassified } \\
\text { arthritis }\end{array}$} & yes & $11(18.64 \%)$ & $10(22.22 \%)$ & $9(45 \%)$ & $0(0 \%)$ & \multirow[t]{2}{*}{7.20} & \multirow[t]{2}{*}{0.07} \\
\hline & no & 48 (81.36\%) & 35 (77.78\%) & $11(55 \%)$ & $4(100 \%)$ & & \\
\hline \multirow[t]{2}{*}{ Neoplasms } & yes & 3 (5.08\%) & $3(6.67 \%)$ & $1(5 \%)$ & $1(25 \%)$ & \multirow[t]{2}{*}{2.60} & \multirow[t]{2}{*}{0.46} \\
\hline & no & 56 (94.92\%) & $42(93.33 \%)$ & $19(95 \%)$ & $3(75 \%)$ & & \\
\hline
\end{tabular}

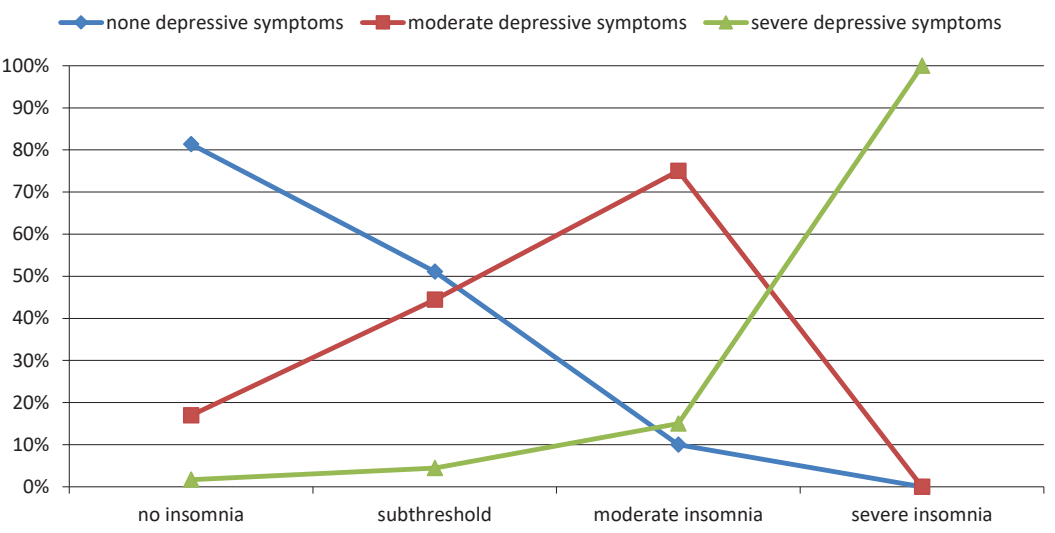

Figure 3. Comparison of Beck Depression Inventory and Insomnia Severity Index

61-70 (4 people $-20 \%$ ), 71-80 (8 people $-40 \%$ ) and $81-90$ ( 1 person $-5 \%)$. Mild insomnia can be found in 4 age ranges: 0-50 (1 person - 2.22\%), 51-60 (7 people - 15.56\%), 61-70 (25 people $-55.56 \%)$, 71-80 (12 people $-26.67 \%$ ). Lack of insomnia can be found in all age ranges: $0-50$ (6 people $-10.17 \%), 51-60$ (21 people $-35.59 \%)$, 61-70 (22 people $-37.29 \%), 71-80$ (9 people $-15.25 \%$ ) and $81-90$ ( 1 person $-1.69 \%)$.

A statistically significant relationship was found between the occurrence of insomnia and depression in women $\left(x^{2}=12.93\right.$; $p=0.005)$. The most common chronic condition among respondents was high blood pressure -62 people $(48.44 \%)$. The least common condition was cancer -8 women (6.25\%) (Table 2).

In the study sample 15 respondents used HRT (11.2\%). In this group of women mild insomnia was diagnosed in 4 respondents (26.7\%), and 11 respondents (73.3\%) did not indicate any sleeping disorders.

A statistically significant strong relationship was found between insomnia and the occurrence of depression symptoms $\left(x^{2}=81.86 ; p<0.001\right)$. The conducted studies suggest a strong relationship between severe depression and severe insomnia. Severe insomnia coexists only with severe depression (4 people $-100 \%)$. Moderate insomnia coexists with 3 types of depression: severe ( 3 people $-15 \%)$, moderate ( 15 people $-75 \%)$, and lack of depression ( 2 people $-10 \%$ ). Mild insomnia coexists with all types of depression: severe ( 2 people $-4.44 \%)$, moderate $(20$ people $-44.44 \%$ ) and lack of depression ( 23 people $-51.11 \%$ ).
Lack of insomnia occurs with: severe depression (1 person $-1.69 \%)$, moderate (10 people $-16.95 \%$ ) and lack of depression (48 people $-81.36 \%$ ) (Figure 3 ).

\section{Discussion}

The authors' own research indicates the occurrence of insomnia in postmenopausal women, and existing relationships between this disorder and age, chronic conditions, HRT, and depression symptoms.

This study emphasised the fact that insomnia occurs in almost $54 \%$ of women. Severe insomnia was diagnosed in $3.12 \%$ of the women, moderate in $15.63 \%$, and mild in $35.16 \%$ of the women. More than one-third of a woman's life is the menopausal and postmenopausal period, and for this reason Zhang et al. have conducted studies on the quality of sleep of women according to their stage of life. Results have shown 4 menopausal statuses (early Menopausal Transition, late Menopausal Transition, early Postmenopause, late Postmenopause), with indications that women in the early Menopausal Transition (early MT) stage had the best quality of sleep. The worst quality of sleep was observed in respondents in the late Postmenopause (late PM) stage. The above data indicate that the group with the highest risk of sleep disorder occurrence is comprised of postmenopausal women [17]. Studies conducted by Kalleinen et al. revealed a higher frequency of insomnia occurrence in the 
postmenopausal stage $(p=0.023)$ rather than in the perimenopausal stage. These results confirm the assumption that studies related to the monitoring of sleep disorders in postmenopausal women are of high value to the scientific world [18].

The results of the authors' own research indicate a statistically significant impact of age on insomnia occurrence. In Zhang et al.'s studies the unidimensional logistic regression showed a significant correlation of age and quality of sleep [17]. In turn, Alföldi et al. noticed a significant co-dependence of higher level of ISI in adults aged 25-64 in comparison to seniors (65 and older) and teenagers (14-24 years old), where the level of ISI values is lower [19]. An increasing tendency of the relationship between age and insomnia occurrence was recorded by Dudzińska et al. Despite $p=0.06$, this relationship was close to being statistically significant [3]. In the representative Polish population of 2413 people (1245 women) aged 18-79 - Nowicki et al.'s studies proved that age has a key influence on the frequency of sleep disorder occurrence [11]. Studies conducted by Ruiz et al. indicate that sleep disorders increase with age. People who are 65 and older had such complaints 1.7 times more often than people aged 18-44. Based on the presented results a conclusion may be drawn that older people are more likely to suffer from insomnia than younger people. The probability of insomnia occurrence increases with the age of respondents [2]. The relationship between age and insomnia occurrence has a different interpretation in Léger et al., where differences were revealed resulting from the respondent's region of residence. In Western Europe and the US there is a higher frequency of sleep disorder occurrence in the group of respondents aged 25-44. In Japan this problem occurs in people aged 55-64 [20]. A different opinion in this matter is presented by Dragioti et al., whose studies have not shown a statistically significant relationship between age and insomnia or its symptoms [21]. Similar results were obtained by Foley et al., where no significant relationship was found between the age of respondents and frequency of sleep disorder occurrence. In their studies an increase in insomnia occurrence along with the age of respondents was only recorded in lowa [9].

The results of the authors' own research indicate the presence of a statistically significant relationship between insomnia and depression revealed by respondents. The remaining chronic conditions included in the questionnaire had no significant importance in relation to insomnia occurrence. However, studies conducted by Foley et al. put emphasis on the fact that sleep disorders increase to ca. $40 \%$ along with co-occurring respiratory symptoms such as coughing, wheezing and phlegm [9]. Occurrence of the above symptoms may indicate asthma or COPD. Studies conducted by Błaszczyk et al. on a group of 1003 people (610 women), residents of Lublin, have indicated that there is a key relationship between high blood pressure and insomnia $\left(x^{2}=120.69 ; p<0.001\right)$ [22]. Work conducted by Green et al. has proven the existence of a statistically significant relationship between occurrence of insomnia and Type 2 diabetes in a group of 1444 respondents [23]. Niu et al.'s studies present a sceptical point of view regarding the impact of shorter sleep cycle and symptoms of insomnia on lower mineral density of bones (BMD). However, scientists point out the need to perform such studies in the future on a larger sample and with an objective evaluation of the sleep of respondents, which would have a positive impact on the development of science [24]. Guo et al.'s studies indicate that 131 respondents (112 women) suffered from rheumatoid arthritis (RA), and 103 of them have bad

Source of funding: This work was funded by the authors' resources. Conflict of interest: The authors declare no conflict of interests. quality of sleep. The occurrence of bad quality of sleep in RA patients (78.6\%) was higher than in the control group (18.7\%) [25]. Based on studies conducted by Wu et al., a conclusion can be drawn that female gender, older age and psoriatic arthritis were independent risk factors in the occurrence of insomnia and depression [26]. George et al. conducted studies on 56 patients with various types of cancer. The most frequent types were colon cancer (18 people), lung cancer (12 people) and breast cancer ( 8 people). Researchers have indicated differences in insomnia occurrence in relation to the type of chemotherapy [27]. The results of Taylor et al.'s studies indicate that respondents suffered from serious sleep disorders. Increase in insomnia symptoms occurred with negative thoughts about the cancer the respondent was diagnosed with [28].

In the authors' own research no statistically significant relationship was found between the use of HRT and insomnia. In the evaluated group only 15 people (11.2\%) had used HRT, and among them 11 women did not suffer from insomnia. The low number of people using HRT may be the result of complications after hormonal therapy, for example, increased blood density or cancer development, mostly ovarian and breast. The above adverse effects prevent women from making the decision related to the use of HRT which could help them eliminate symptoms, decrease the risk of osteoporotic fractures, or the frequency of colon cancer occurrence [29]. Similar result were obtained by $\mathrm{Xu}$ et al., where female respondents using HRT did not reveal significantly better sleep than respondents not using HRT. However, hormone level evaluation in a larger sample of women may become the subject of future studies [30]. Studies conducted by Saletu-Zyhlarz et al. revealed that the total amount of sleep and its efficacy increased after applying Climodien and Estradiol, but they remained unchanged with the placebo. Unfortunately, the described changes did not reach a statistically significant level [31].

The authors' own research has revealed a strong statistically significant relationship between insomnia occurrence and depression symptoms found with the Beck Depression Inventory. Similar results were obtained by Desai et al., where depression and anxiety symptoms were the key risk factors in insomnia occurrence. They claim that the above results may recommend depression and anxiety treatment which would improve sleep [32]. In Toffol et al.'s studies on perimenopausal and postmenopausal women, depression symptoms were related to sleep disorders [7]. Sleep disorders such as waking up too early or problems with falling asleep are typical depression symptoms. Studies conducted by Wolińska et al., where a statistically significant relationship was found between these two variables, suggest that insomnia may increase depression symptoms [1].

\section{Limitations of the study}

Only respondents who were students at the University of the Third Age were invited to participate in the study, and for this reason this sample was not representative for the entire population of postmenopausal women in Poland.

\section{Conclusions}

Risk factors predisposing patients to the occurrence of insomnia are age and depression symptoms. However, the use of HRT and pre-existing chronic conditions have no key influence on the occurrence of insomnia. 


\section{References}

1. Wolińska W, Pawlak IE, Mroczek B. Analysis of insomnia in those over 60 year of age. Fam Med Prim Care Rev 2016; 18(4): $482-485$.

2. Ruiz AJ, Rondon Sepúlveda MA, Franco OH, et al. The associations between sleep disorders and anthropometric measures in adults from three Columbian cities at different altitudes. Maturitas 2016; 94: 1-10.

3. Dudzińska M, Neć M, Zwolak A, et al. Bezsenność - istotny problem w codziennej praktyce lekarskiej - doniesienie wstępne. Fam Med Prim Care Rev 2015; 17(2): 90-93 (in Polish).

4. Pużyński S, Wciórka J. Klasyfikacja zaburzeń psychicznych i zaburzeń zachowania w ICD-10. Opisy kliniczne i wskazówki diagnostyczne. Kraków - Warszawa: Uniwersyteckie Wydawnictwo „Vesalius”, Instytut Psychiatrii i Neurologii; 2000 (in Polish).

5. Wojtas A, Ciszewski S. Epidemiologia bezsenności. Psychiatria 2011; 8(3): 79-83 (in Polish).

6. Ostrowska A, Żmijewska-Jędrzejczyk T. Bezsenność w Europie. In: Sztabiński PB, ed. Polska-Europa. Wyniki europejskiego sondażu spotecznego 2002-2015. Warszawa: Wydawnictwo Instytutu Filozofii i Socjologii PAN; 2016: 91-99 (in Polish).

7. Toffol E, Kalleinen $\mathrm{N}$, Urrila AS, et al. The relationship between mood and sleep in different female reproductive states. BMC Psychiatry 2014; 14(177): 1-13.

8. Ensrud KE, Guthrie KA, Hohensee $C$, et al. Effects of estradiol and venlafaxine on insomnia symptoms and sleep quality in women with hot flashes. Sleep 2015; 38(1): 97-108.

9. Foley DJ, Monjan AA, Brown SL, et al. Sleep complaints among elderly persons: an epidemiologic study of three communities. Sleep 1995; 18(6): 425-432.

10. Heitzman J. Zaburzenia snu - przyczyna czy skutek depresji? Psychiatr Pol 2009; 46(5): 499-511 (in Polish).

11. Nowicki Z, Grabowski K, Cubała WJ, et al. Rozpowszechnienie subiektywnej bezsenności w populacji polskiej. Psychiatr Pol 2016; 50(1): 165-173 (in Polish).

12. Monterrosa-Castro Á, Portela-Buelvas K, Salguedo-Madrid M, et al. Instruments to study sleep disorders in climacteric women. Sleep Sci 2016; 9(3): 169-178.

13. Bastien $\mathrm{CH}$, Vallières $\mathrm{A}$, Morin $\mathrm{CM}$. Validation of the Insomnia Severity Index as an outcome measure for insomnia research. Sleep Med 2001; 2(4): 297-307.

14. Savard MH, Savard J, Simard S, et al. Empirical validation of the Insomnia Severity Index in cancer patients. Psychooncology 2005; 14(6): 429-441.

15. Beck AT, Ward CH, Mendelson M, et al. An inventory for measuring depression. Arch Gen Psychiatry 1961; 4: 561-571.

16. Parandowski T, Jernajczyk W. Inwentarz depresji Becka w ocenie nastroju osób zdrowych i chorych na choroby afektywne (ocena pilotażowa). Psychiatr Pol 1977; 11(4): 417-424.

17. Zhang J, Wang Y, Yan M, et al. Menopausal symptoms and sleep quality during menopausal transition and postmenopause. Chin Med J 2016; 129(7): 771-777.

18. Kalleinen N, Polo-Kantola P, Himanen S, et al. Sleep and the menopause - do postmenopausal women experience worse sleep than premenopausal women? Menopause Int 2008; 14(3): 97-104.

19. Alföldi P, Dragioti E, Wiklund T, et al. Spreading of pain and insomnia in patients with chronic pain: results from a national quality registry (SQRP). J Rehabil Med 2017; 49: 63-70.

20. Léger D, Poursain B, Neubauer D, et al. An international survey of sleeping problems in the general population. Curr Med Res Opin 2008; 24(1): 307-317.

21. Dragioti E, Levin L, Bernfort L, et al. Insomnia severity and its relationship with demographics, pain features, anxiety, and depression in older adults with and without pain: cross-sectional population-based results from the PainS65+ cohort. Ann Gen Psychiatry 2017; 16(15): 1-10.

22. Błaszczyk R, Wysokiński A, Ciota M, et al. Zaburzenia snu oraz senność dzienna u pacjentów z nadciśnieniem tętniczym. Pol Prz Kardiol 2010; 12(2): 109-115 (in Polish).

23. Green MJ, Espie CA, Popham F, et al. Insomnia symptoms as a cause of type 2 diabetes Incidence: a 20 year cohort study. BMC Psychiatry 2017; 17(94): 1-8.

24. Niu J, Sahni S, Liao S, et al. Association between sleep duration, insomnia symptoms and bone mineral density in Older Boston Puerto Rican Adults. PLoS One 2015, doi: 10.1371/journal.pone.0132342.

25. Guo G, Fu T, Yin R, et al. Sleep quality in Chinese patients with rheumatoid arthritis: contributing factors and effects on health-related quality of life. Health Qual Life Outcomes 2016; 14(151): 1-8.

26. Wu C, Chang Y, Juan C, et al. Depression and insomnia in patients with psoriasis and psoriatic arthritis taking tumor necrosis factor antagonists. Medicine (Baltimore) 2016; 95(22): 1-9.

27. George M, Elias A, Shafiei M. Insomnia in cancer - associations and implications. Asian Pac J Cancer Prev 2015; 16(15): 6711-6714.

28. Taylor TR, Huntley ED, Makambi K, et al. Understanding sleep disturbances in African-American breast cancer survivors: a pilot study. Psychooncology 2012; 8: 896-902.

29. Suchecka-Rachoń K, Rachoń D. Rola hormonalnej terapii zastępczej (HTZ) u kobiet w okresie pomenopauzalnym. Chor Serca Naczyń 2005; 2(3): 115-124.

30. Xu M, Bélanger $\mathrm{L}$, Ivers $\mathrm{H}$, et al. Comparison of subjective and objective sleep quality in menopausal and non-menopausal women with insomnia. Sleep Med 2011; 12(1): 65-69.

31. Saletu-Zyhlarz G, Anderer P, Gruber G, et al. Insomnia related to postmenopausal syndrome and hormone replacement therapy: sleep laboratory studies on baseline differences between patients and controls and double-blind, placebo-controlled investigations on the effects of a novel estrogen-progestogen combination (Climodien ${ }^{\circledR}$, Lafamme ${ }^{\circledR}$ ) versus estrogen alone. J Sleep Res 2003; 12(3): $239-254$.

32. Desai K, Mao JJ, Su I, et al. Prevalence and risk factors for insomnia among breast cancer patients on aromatase inhibitors. Support Care Cancer 2013; 21(1): 43-51.

Tables: 2

Figures: 3

References: 32

Received: 08.05.2017

Revised: 27.05.2017

Accepted: 12.06 .2017
Address for correspondence:

Iwona Ewa Karpeta-Pawlak, MA

Zakład Nauk Humanistycznych w Medycynie PUM

ul. gen. Dezyderego Chłapowskiego 11

70-103 Szczecin

Tel.: +48 514 371-596

E-mail: iwona.pawlak@pum.edu.pl 